\title{
Amorphophallus gigas blüht erstmals im Palmengarten
}

\author{
Hilke Steinecke
}

\begin{abstract}
Amorphophallus gigas is one of the tallest growing species in the genus. Its major distinguishing feature is the elongated peduncle on which the fetid-smelling inflorescence is borne. First-time blooming at the Palmengarten occurred in March 2016.
\end{abstract}

\section{Zusammenfassung}

Amorphophallus gigas gehört zu den besonders großen Vertretern der Gattung Amorphophallus. Von A. titanum unterscheidet sich die Art vor allem durch den lang gestielten Blütenstand. Im Palmengarten kam im März 2016 A. gigas erstmals zur Blüte.

\section{Amorphophallus im Palmengarten}

Der Palmengarten beherbergt eine artenreiche Amorphophallus(Titanenwurz)-Sammlung. Die meisten Individuen dieser zu den Aronstabgewächsen (Araceae) gehörenden Gattung werden in der nicht zugänglichen botanischen Sammlung kultiviert. Zur Blütezeit wird aber die eine oder andere Art temporär auch in den Schauhäusern ausgestellt. Die überwiegend in tropischen Regenwäldern verbreitete Gattung Amorphophallus umfasst etwa 90 Arten, von denen rund 40 im Palmengarten vorhanden sind. Darunter ist auch der auf Madagaskar heimische und erst 2003 beschriebene $A$. mangelsdorffi. Bekanntester Vertreter ist die Titanenwurz ( $A$. titanum) aus Sumatra, die regelmäßig fast jährlich im Palmengarten zur Blüte kommt. Der etwa $3 \mathrm{~m}$ hohe, nahezu ungestielte Blütenstand von $A$. titanum hält sich je nach Temperatur und Sonneneinwirkung nur 1-3 Tage und stinkt dann intensiv nach Aas. Es ist im Palmengarten wie auch in anderen Botanischen Gärten immer wieder eine Meldung wert, wenn ein Amorphophallus titanum blüht. Viele Interessenten kommen zu dem Blühereignis, wie in den letzten Jahren z. B. auch in den Botanischen Gärten Köln und Bayreuth deutlich wurde, wo diese Art zum ersten Mal blühte.

Abb. 1: Amorphophallus gigas mit jungem, geschlossenem Blütenstand in der botanischen Sammlung.

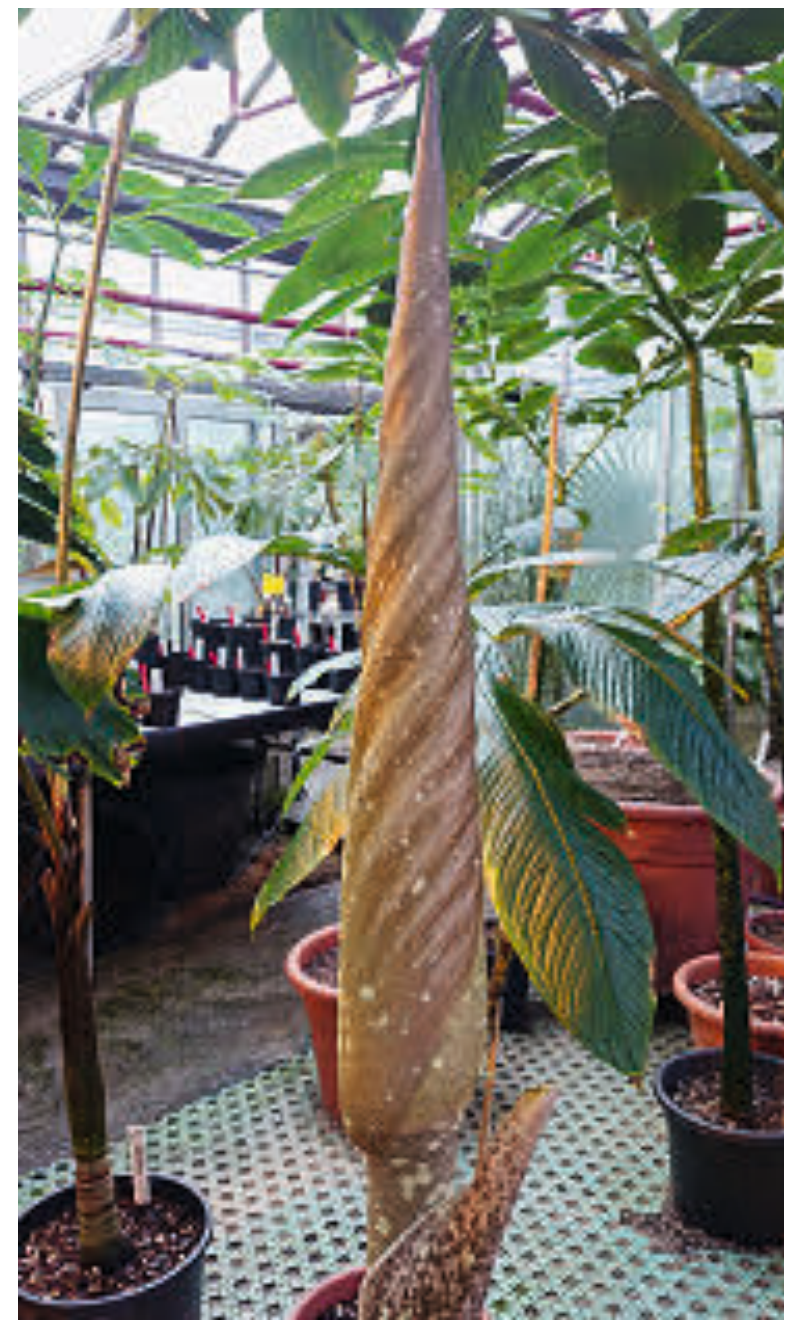

\section{Amorphophallus gigas}

Es ist natürlich besonders spannend, wenn selten kultivierte Pflanzen in einem Garten erstmals zur Blüte kommen. So entwickelte im Winter 2015/2016 im Palmengarten Amorpho- 

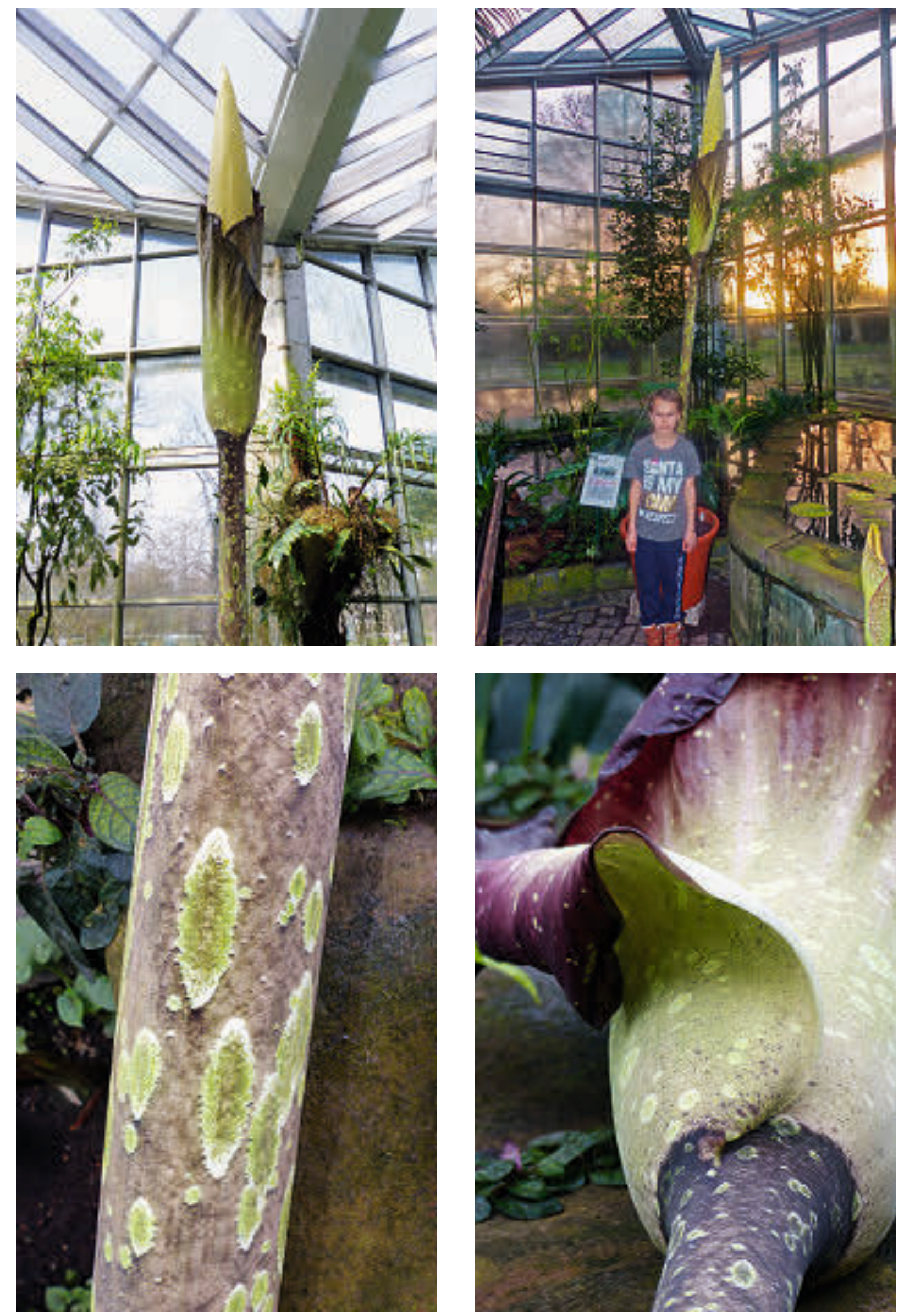


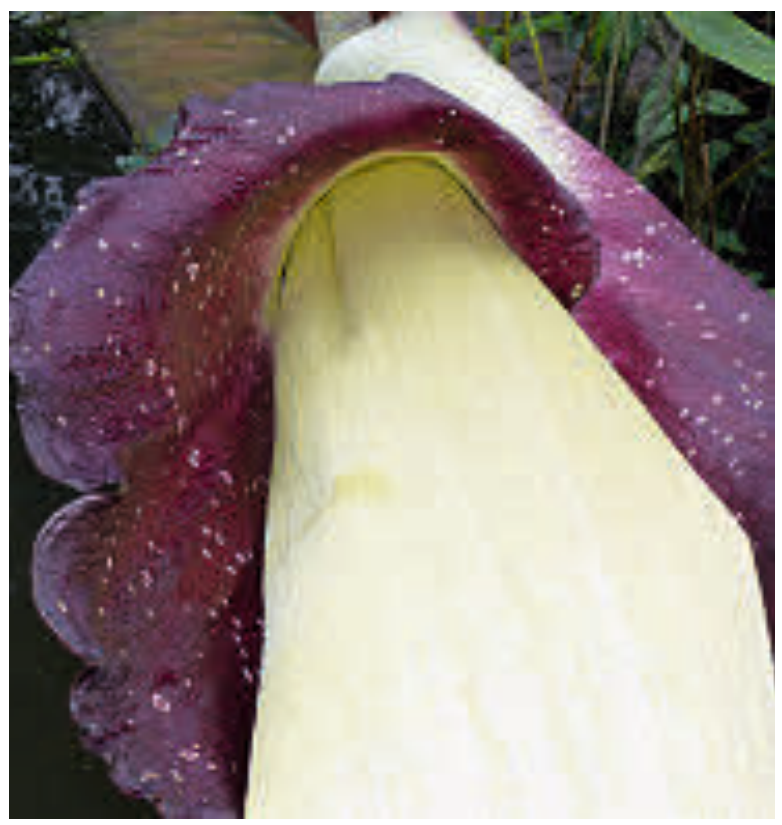

phallus gigas erstmals einen Blütenstand. Diese große Amorphophallus-Art ist nicht weniger spektakulär als $A$. titanum, aber erst seit viel kürzerer Zeit in Kultur. Denn erst 1994 wurde Amorphophallus gigas vom Amerikaner James Symon und dem Niederländer Wilbert HetTERSCHEID auf ihrer Sumatra-Expedition 1993 für die Kultur gesammelt. Aus den Samen wurden in diversen Botanischen Gärten Pflanzen herangezogen, die anschließend u. a. auch vegetativ weiter vermehrt wurden. Einer der ersten Gärten, in denen $A$. gigas blühte, ist der Fairchield Tropical Garden (Miami, Florida). Zum erfolgreichen Blühereignis gratulierte der Araceen-Spezialist Hetterscheid: „Congrats with this excellent result! Let's face it, blooming A. titanum is a child's job ... but gigas, that is a

Abb. 2 (Seite 48 oben links): Amorphophallus gigas mit älterem Blütenstand, Kolben sichtbar.

Abb. 3 (Seite 48 oben rechts): Lang gestielter Blütenstand mit Größenvergleich.

Abb. 4 (Seite 48 unten links): Der Blütenstandsstiel ist gefleckt und wirkt, als wenn er von Moosen oder Flechten bewachsen wäre.

Abb. 5 (Seite 48 unten rechts): Seitlicher Blick auf den geöffneten Blütenstand.

Abb. 6 (links): Kolben und Hochblatt.

Abb. 7 (rechts): Blick in den Blütenstand.

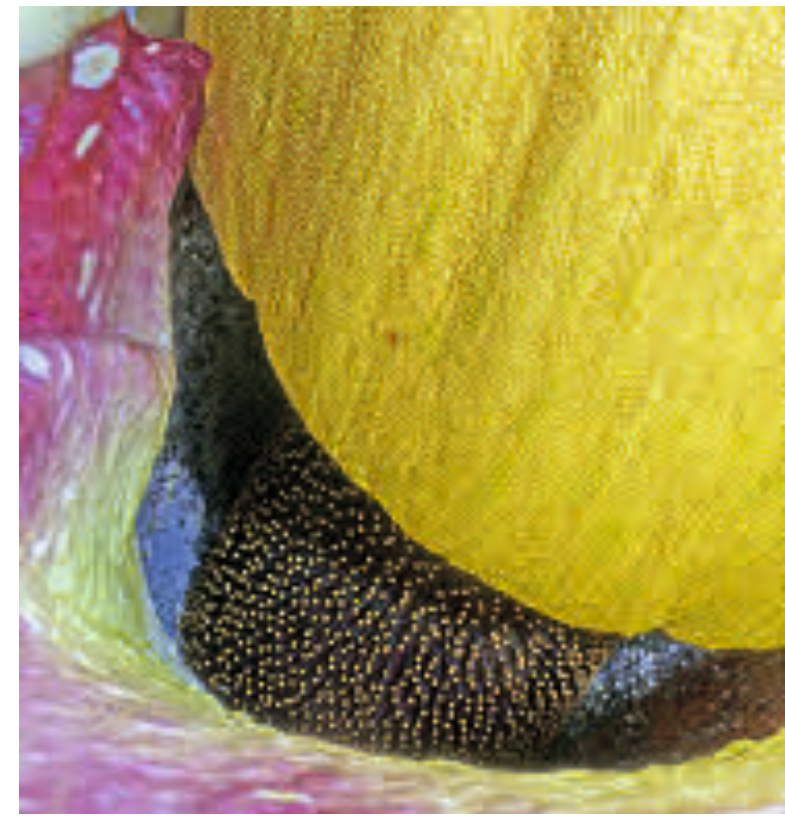

different story. So far, there at our latitude, it has been extremely difficult to keep gigas alive."

Auch unser Amorphophallus gigas ist letztendlich ein Abkömmling der Aufsammlung von 1993 aus Indonesien. Die Pflanze ist seit 2010 bei uns in Kultur. In unserer Sammlung gibt es noch zwei weitere Knollen, die bisher aber noch nicht zur Blüte gekommen sind. Wie auch andere Amorphophallus-Arten hat A. gigas Knollen, aus denen entweder ein einziges Blatt oder ein Blütenstand austreibt. Das Fiederblatt hat einen kräftigen Stiel, wird um die $2 \mathrm{~m}$ hoch und ist baumförmig verzweigt.

\section{Der Blütenstand öffnet sich}

Der Blütenstand entwickelte sich aus einer nur rund $5 \mathrm{~kg}$ schweren Knolle. Wegen des trüben und kühlen Wetters streckte er sich nur langsam, das Aufblühen wurde im Zeitraum um Ende Februar bis Anfang März erwartet. Im Gegensatz zu A. titanum ist die Infloreszenz lang gestielt. Der Stiel erreichte eine Länge von rund 1,60 m, während der von der Spatha umgebene Kolben sich auf eine Länge von rund $1,45 \mathrm{~m}$ streckte. Der Infloreszenzstiel ist ähnlich wie auch der Blattstiel hellgrün gefleckt. Durch diese Musterung wird ein älterer, stabiler Stamm mit Flechten- oder Moosbewuchs imitiert, wodurch Fressfeinde abgeschreckt werden. 


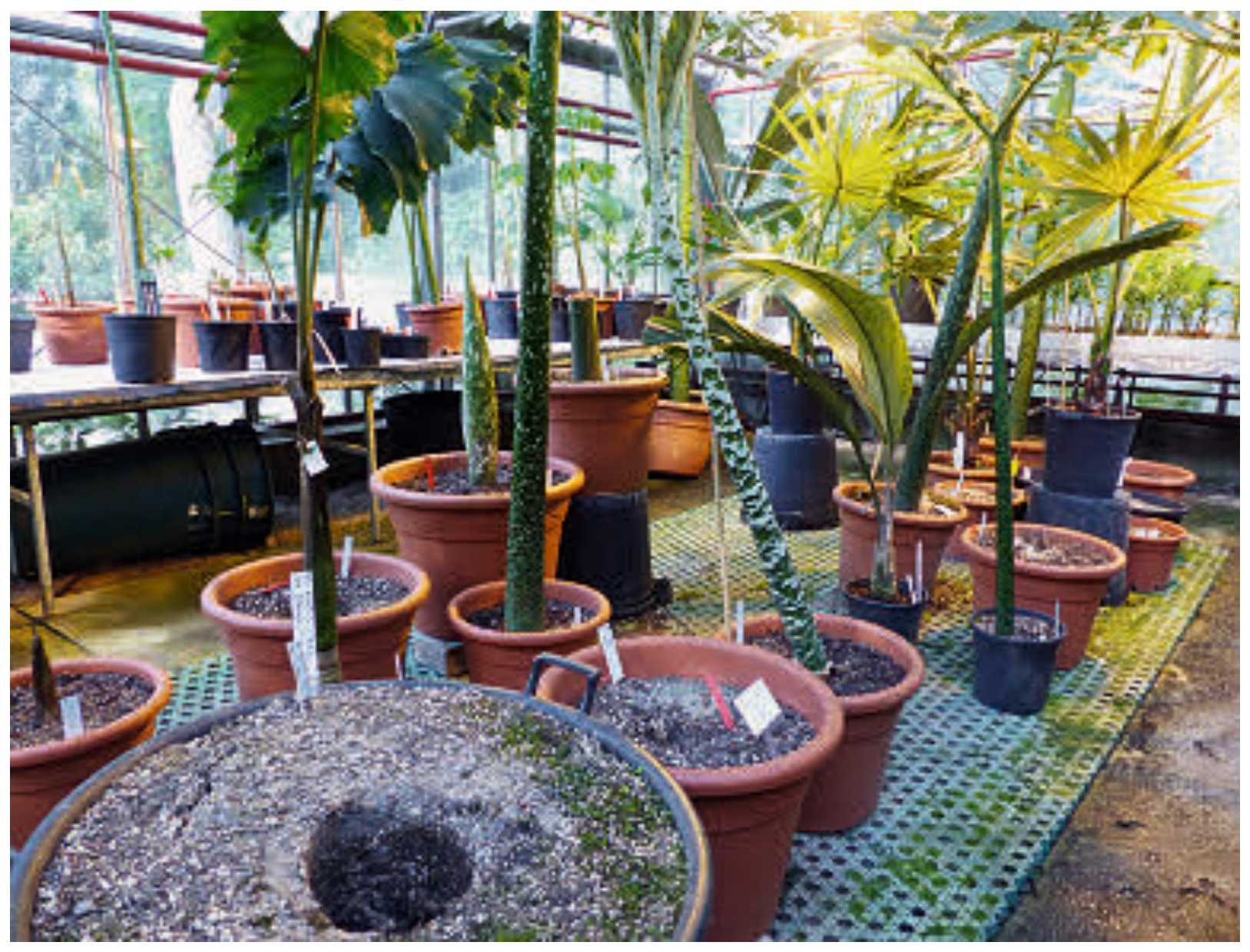

Das den Blütenstand umgebende Hochblatt (Spatha) übernimmt die Schauwirkung und ist außen gelblich grün gefärbt mit hellen Flecken. Ähnlich wie bei $A$. titanum ist es wie ein Reifrock in Falten gelegt. Innen ist es dunkelrot gefärbt mit weißen Punkten. Wenn sich die Spatha geöffnet hat, zeigt auch der nach außen gebogene äußere Rand eine rötliche Färbung.

Im unteren Bereich des Blütenstandes befinden sich viele unscheinbare weibliche Blüten, darüber stehen die männlichen. Die obere gelbe Hälfte des Kolbens ist steril. Die Blütenstände verbreiten einen aasartigen Gestank, der Käfer oder Aasfliegen anlockt. Im sterilen Teil des Kolbens wird Wärme produziert, die den Blütengeruch besser verteilt.

Bis zum 4. März hatte sich die Infloreszenz immer noch etwas gestreckt. Leider war der obere Teil so schwer und der innen schwammige Blütenstandstiel für diese Last nicht stabil genug, sodass der Blütenstand in der Nacht vom 5. auf den 6. März umgeknickt ist. Trotz- dem blühte $A$. gigas einen Tag später, wenn auch niederliegend, noch auf und verströmte seinen unangenehmen Gestank nach Aas. Trotz dieses „Unfalls“ konnte die spannende Blütenbiologie nachvollzogen werden und beeindruckte viele Gartenbesucher.

Wenige Tage nach dem Verblühen, wenn keine Bestäubung erfolgt ist, schrumpelt der Blütenstand ein. Die Knolle braucht nun eine Ruhephase und wird nach einiger Zeit mit einem neuen Blatt austreiben.

\section{Internetseite}

http://www.virtualherbarium.org/amorph/Agigas.html

Abb. 8: Blick auf einen Teil der Titanenwurz-Sammlung. In der ersten Reihe im zweiten Topf von links befindet sich eine Knolle von Amorphophallus gigas. 